\title{
O detetive híbrido: inovação tecnológica e tradição na investigação criminal
}

The hybrid detective - technological innovation and tradition in criminal investigation

\author{
Diana Miranda ${ }^{1}$ \\ Helena Machado ${ }^{2}$
}

Artigo recebido em para publicação em set./2013 e aceito para publicação em maio/2014

\begin{abstract}
RESUMO
Neste artigo são exploradas as narrativas dos inspetores da Polícia Judiciária (PJ) relativamente aos processos de vigilância e identificação de suspeitos de crime. Recorrendo a uma perspetiva teóricometodológica do tipo interpretativo e qualitativo, deseja-se mapear o sentido e compreender 0 significado que os inspetores da PJ atribuem às suas práticas no decurso da investigação criminal. $\mathrm{A}$ aplicação da ciência e da tecnologia na investigação criminal exige uma reflexão em torno dos impactos que estas acarretam. Apesar do potencial uso da ciência e tecnologia na investigação criminal, confrontamo-nos com uma série de obstáculos que nos demonstram os limites deste processo de cientifização. As novas tecnologias de recolha e manuseamento de informação sobre suspeitos e condenados por crime complementam os meios tradicionais de investigação criminal, criando-se assim uma figura híbrida do detetive policial.
\end{abstract}

Palavras-chave: Ciência. Identificação. Investigação criminal. Tecnologia. Vigilância.

\begin{abstract}
In this paper we explore the narratives of the Portuguese Criminal Investigation Police (Polícia Judiciária) about surveillance and identification aimed at crime suspects. Through an interpretive and qualitative theoretical-methodological perspective, we aim to understand the views of these agents concerning police practices of criminal investigation. The application of scientific knowledge and the technology to criminal investigation requires a reflection of its impacts. Despite the potential use of science and technology in criminal investigation, we face a set of obstacles that shows the limits of this scientificization process. The new technologies of collection and use of information about suspects and convicted offenders complement the traditional means of criminal investigation, thus creating a hybrid figure of detective.
\end{abstract}

Keywords: Criminal investigation. Identification. Science. Surveillance. Technology.

1 Licenciada em Sociologia pela Universidade do Minho (UM), com pós-graduação em Criminologia pela Faculdade de Direito da Universidade do Porto (UP). Desenvolve doutoramento em Sociologia na Universidade do Minho (UM) com o projeto "A identificação criminal e a identidade do criminoso: percepções de reclusos e agentes de controlo sobre as práticas de vigilância e classificação do corpo delinquente". E-mail: dianam@ics.uminho.pt.

2 Licenciatura em Sociologia pela Universidade de Coimbra, Mestrado em História das Populações pela Universidade do Minho e Doutoramento em Sociologia pela Universidade do Minho com a tese "Tribunais, género, ciência e cidadania - uma abordagem sociológica da investigação judicial de paternidade". Professora Associada com Agregação do Departamento de Sociologia da Universidade do Minho. Investigadora FCT (Consolidation Grant) do Núcleo de Estudos de Ciência, Economia e Sociedade do Centro de Estudos Sociais - Universidade de Coimbra. Email: helenamachado@ces.uc.pt. 


\section{INTRODUÇÃO}

A crença na ciência e tecnologia torna possível a implementação de novas tecnologias de vigilância como ferramentas de apoio no trabalho policial (ABE, 2006; BYRNE; MARX, 2011; DEN BOER, 2011; ERICSON; HAGGERTY, 1997; VAN BRAKEL; HERT, 2011) e o crescente recurso a bases de dados nas práticas policiais exemplifica a confiança na tecnologia de vigilância. Torna-se assim possível armazenar e processar informação de modo mais eficiente, podendo estas tecnologias assumir parte das tarefas policiais (VAN BRAKEL; HERT, 2011). Além do uso ubíquo dessas tecnologias de processamento de informação, destaquem-se ainda as tecnologias de identificação (impressões digitais, perfis genéticos, entre outros) e o seu impacto na investigação criminal.

Partindo de contributos teóricos dos estudos sociais da ciência e tecnologia, dos estudos da vigilância e policiamento é possível compreender o impacto da ciência e da tecnologia nas práticas policiais contemporâneas e analisar o caso particular da investigação criminal. Em Portugal, há trabalho desenvolvido em torno de práticas de vigilância e identificação criminal, nomeadamente o estudo das perspetivas dos vigilantes a respeito do uso do DNA na investigação criminal (COSTA, 2012; MACHADO; COSTA, 2012) e do uso da videovigilância (FROIS, 2013). É necessário, contudo, obter uma visão mais alargada do olhar daqueles que vigiam em relação às suas práticas.

Tendo por base o crescente uso de tecnologias de vigilância pela polícia, almeja-se com este artigo explorar as narrativas dos inspetores da $\mathrm{PJ}^{3}$ relativamente aos processos de vigilância e identificação no decurso da investigação criminal. Debruçando o olhar na relação tecnologia e sociedade, é de extrema importância analisar a forma como os sujeitos sociais adaptam, moldam e se apropriam da tecnologia (LATOUR, 1992). É necessário refletir sobre os impactos da aplicação da ciência e da tecnologia na investigação criminal, procurando compreender 0 processo de cientifização policial em Portugal e os obstáculos colocados. A conjugação dos meios tradicionais com as novas tecnologias de recolha e gestão de informação é uma dimensão de análise fundamental.

3 Em Portugal, a Polícia Judiciária é o órgão de polícia criminal com competência para a investigação da maioria dos crimes (artigo 7.. da Lei n.. 49/2008). 


\section{O PAPEL DA CIÊNCIA E DA TECNOLOGIA NA INVESTIGAÇÃO CRIMINAL}

A abordagem empiricista da ciência transporta-nos para um mundo em que a ciência nos permite descobrir a verdade. Esta crença na ciência e tecnologia como forma de alcançar a verdade e eficácia na investigação criminal (VAN BRAKEL; HERT, 2011; WILLIAMS; JOHNSON, 2008) está patente no discurso dos inspetores entrevistados. Quando questionados quanto ao papel da ciência e da tecnologia na investigação criminal, os inspetores referem como tal permite obter mais informação e com maior celeridade, representando deste modo uma grande ajuda na investigação criminal. A ciência é tida como irrefutável e tal é evidenciado nas palavras do inspetor Baltasar: "o que é científico é comprovado e ninguém o refuta, daí que sempre que seja possível o investigador se socorra desses elementos [...] para justificar e comprovar para não haver dúvidas".

O trabalho policial é multidisciplinar e, segundo o inspetor Carlos, os investigadores têm que "saber um bocadinho de tudo" e "só se compreende que beba em várias ciências". Desde a balística, à química, biologia, entre outras, podem ser efetuados diversos exames com resultados que representam um argumento cientificamente comprovado e sem qualquer refutação. Tal como refere o inspetor Guilherme, "a ciência permite-nos com mais probabilidade determinar que as coisas são assim porque é científico, quer dizer é provado".

A prova científica tida como objetiva e neutra surge para os inspetores como algo que poderá dar credibilidade e legitimidade às suas convicções e ações (ERICSON; SHEARING, 1986; JOHNSON; WILLIAMS; MARTIN, 2003), sendo assim necessária para evidenciar a "versão" da polícia (KRUSE, 2012; McCARTNEY, 2006). As novas tecnologias geram imenso entusiasmo e podem assim alterar o modo como as instituições de justiça criminal, nomeadamente a polícia "will make their decisions based on scientific knowledge rather than guesswork, prejudice, or intuition" (COLE, 2001, p. 303). O inspetor Rui, analista de informação criminal da área estratégica e operacional, referiu precisamente isto: "já não vamos lá com intuição. Isso já foi tempo, não é?"4"

O policiamento pode moldar ou ser moldado pelo recurso a novas tecnologias, sendo estas um dispositivo de transformação do trabalho policial. Efetivamente, os inspetores têm de recorrer a sofisticadas técnicas de base científica

4 Enalteça-se, contudo, que apesar da crença na objetividade e neutralidade da ciência, esta guia-se por uma versão que já tem determinado suspeito como alvo (McCARTNEY, 2006). 
que exigem a adoção de saberes e tecnologias específicas, o que evidencia uma cultura profissional própria que tem por base a cientifização. A cientifização do trabalho policial (ERICSON; SHEARING, 1986) implica a adoção de elementos tecnológicos que alteram a natureza desse trabalho, tornando a investigação criminal mais rápida e eficaz. Os inspetores podem ser encarados como "agentes técnicos da racionalidade científica" (ERICSON; SHEARING, 1986; JOHNSON; WILLIAMS; MARTIN, 2003; WILLIAMS; JOHNSON, 2008), sendo que pela proclamada eficácia das novas tecnologias se submetem à racionalidade cognitivoinstrumental da ciência (SANTOS, 2000 apud MACHADO, 2012, p. 67). Contudo, em Portugal são diversos os obstáculos que se colocam à cientifização do trabalho policial (COSTA, 2012; MACHADO; COSTA, 2012; MACHADO; SANTOS, 2012).

\section{METODOLOGIA}

Recorrendo a uma metodologia qualitativa e adotando uma abordagem compreensiva, foram realizadas 14 entrevistas semiestruturadas a inspetores da PJ entre outubro de 2012 e junho de 2013. Apesar da seleção dos entrevistados ter ocorrido através de um efeito bola de neve e sempre sujeita à disponibilidade dos inspetores, atendeu-se a um requisito de diversidade de modo a garantir a heterogeneidade dos entrevistados pelos seguintes critérios: a escolha da unidade orgânica (1 unidade local de investigação criminal, 1 regional e 1 territorial), o tipo de criminalidade com que lidam (criminalidade sexual, económica, homicídio, roubo e tráfico de estupefacientes) ou a área de trabalho (área estratégica e operacional de informação), o tempo de exercício da atividade profissional (entre os 3 e os 32 anos) e o sexo (10 do sexo masculino e 4 do sexo feminino).

Para realizar as entrevistas efetuou-se um pedido de obtenção de consentimento informado para participação no estudo. Dois inspetores rejeitaram a gravação áudio, tendo sido no final registadas as informações prestadas enquanto produto de memorização e notas tiradas. As restantes 12 entrevistas foram transcritas e tiveram uma duração média de 1 hora e 30 minutos. De modo a preservar o anonimato dos entrevistados, todos os nomes usados na apresentação dos excertos de entrevista são ficcionais. 


\section{“UM BICHO DE SETE CABEÇAS"}

Nem sempre é possível recorrer ao testemunho da ciência e da tecnologia devido a imensos obstáculos, sendo um deles a falta de recursos tecnológicos. Tal como disse o inspetor Rui, "a PJ já não investe em tecnologia de forma abrangente há uma década, [pois] não tem havido dinheiro para isso".

A legislação restritiva e a falta de colaboração no acesso e partilha de informação são outros obstáculos. Nas palavras do inspetor Simão, "nós temos um regime extraordinariamente rigoroso no que concerne aos direitos, liberdades e garantias e que nos tolda, mas tolda-nos cegamente a nossa capacidade de investigação no acesso às bases de dados".

É de realçar a este propósito que os órgãos de polícia criminal têm cada um o seu arquivo e sistema de informação. A inspetora Joana acha que a "conjugação ou compilação de toda a informação que todas as polícias têm" é extremamente importante, já que "parece que cada polícia trabalha para si [apenas]".

\footnotetext{
Nós temos aqui uma quintinha, temos [...] informação, somos muito ciosos dela e é nossa. E, em Portugal, esta cultura de partilhar a informação [...] não existe. Existe muito outra de círculos fechados, cada um tem a sua informação e a informação porque nos dá poder fica no nosso seio. (Inspetor Carlos)
}

Esta não-partilha de informação ocorre também dentro da própria instituição, dado que por vezes há um desconhecimento das capacidades de algumas unidades pertencentes à $\mathrm{PJ}$, nomeadamente os serviços de polícia científica e técnica.

Muitas das vezes o nosso LPC [Laboratório de Polícia Científica] e algumas das nossas unidades (...) têm valências e têm capacidades que nós desconhecemos. [...] As pessoas têm aquela capacidade, a quinta é delas e elas contém aquela informação. Ou seja, não há uma cultura de dizer assim "isto é meu, é de todos". (Inspetor Simão)

Parece haver assim um desencontro entre a investigação criminal e a ciência e tecnologia, sendo tal evidenciado pelo discurso dos inspetores:

\footnotetext{
É assim, eu sou todo a favor que haja mais ciência e mais tecnologia cá, até porque nos permite evoluir sempre. Às vezes são é caminhos que andam um bocado desencontrados. Porque às vezes [...] o pessoal da investigação não está se calhar sensibilizado para até aplicar alguma coisas que existem. Outras vezes, elas existem, mas não são de aplicação fácil, por exemplo. É "um bicho de sete cabeças" para fazer qualquer coisa.
}

Um outro exemplo deste "bicho de sete cabeças" prende-se com a resistência à novidade no mundo jurídico. Os inspetores deixam claro que um investigador de 
gerações mais antigas fica desfasado da realidade caso não se "abra à mudança". Aliás, nas palavras do inspetor Daniel, "o mundo jurídico é um mundo muito adverso à mudança. E se as polícias não gostam muito da mudança, [...] os tribunais ainda gostam menos". No "mundo jurídico" há usualmente um certo conservadorismo e apenas quando a técnica científica começa a ser frequentemente usada é que é aceite. Efetivamente, as inovações passam por um trajeto que implica contestação, contingência e adaptação (JOHNSON; WILLIAMS; MARTIN, 2003; WILLIAMS; JOHNSON, 2004).

Entre juízes e sacerdotes a diferença não é muita, relativamente aos processos e à revolução científica a coisa joga mais ou menos pelo mesmo caminho e para eles isto do ADN tem de ser aquela coisa... a interdição e não sei quê. (Inspetor Simão)

O inspetor Simão refere a possibilidade de recorrer aos perfis genéticos, ilustrando o crescente uso de informação biológica e a implementação de novas técnicas de vigilância biométricas. Os perfis genéticos surgem como uma das novas formas da polícia proceder à identificação dos indivíduos mas é referida a resistência e a desconfiança perante estas técnicas e como estão ainda numa fase embrionária. Nas palavras do inspetor Carlos, "ainda está muito tenro, ainda muito verde". De facto, tal como refere Catarina Frois (2008, p. 112), Portugal está ainda "numa fase de execução no que concerne à implementação de sistemas de vigilância com base na tecnologia".

\section{A TRADIÇÃO E A INOVAÇÃO}

No que respeita às práticas de vigilância e controlo, os meios de obtenção de informação podem ser distinguidos em meios soft e meios hard. Os meios soft relacionam-se com o ethos da nova vigilância (MARX, 2008) e afiguram-se na atualidade como a crescente aposta pela sua automatização e invisibilidade (BYRNE; MARX, 2011; MARX, 2008). Associados à vigilância tradicional, os meios hard são tidos como "duros", mais visíveis e até invasivos. O que se constata nas transformações que têm ocorrido nestas práticas é que "ao mesmo tempo que não se verifica qualquer abrandamento das formas «duras» de controlo, as formas soft estão a expandir-se de várias formas" (MARX, 2008, p. 88).

Com efeito, o recurso aos meios tradicionais de recolha e gestão de informação perdura e estes não serão substituídos pelos meios mais recentes 
(COLE; LYNCH, 2006; MCCARTNEY, 2006; MACHADO; PRAINSACK, 2012; MARX, 2008; PURENNE, 2012). A inspetora Joana referiu, precisamente, que apesar de achar os "métodos inovadores [...] muito importantes vai-se sempre beber aos mais antigos." A vigilância tradicional passa assim a ser complementada por uma nova vigilância, automatizada e menos visível (LYON, 2001; MARX, 2008), fazendo surgir uma figura de detetive híbrida, filha de dois tempos diferentes: passado e presente.

\section{“É CARREGAR NO BOTÃo E DEIXAR PROCURAR, NÃO É?”}

A rudimentaridade, morosidade e falibilidade são usualmente associadas aos meios tradicionais. Enquanto no passado tudo teria de ser averiguado manualmente e ao nível local, no presente a informática permite a averiguação automática ao nível nacional e até internacional. Tal como diz o inspetor Filipe, "lá está, é a velha questão, tudo em termos tecnológicos que possa agilizar, facilitar... epá é carregar no botão e deixar procurar, não é?".

A expansão da computorização e tecnologias de comunicação tem imenso impacto na recolha e registo de informação policial (ABE, 2006; BYRNE; MARX, 2011; CEYHAN, 2005; VAN BRAKEL E HERT, 2011), sendo a informatização um instrumento essencial no processo de vigilância pelo registo permanente de conhecimento. As bases de dados destacam-se neste processo e tal remete-nos para o conceito de Latour (2001) de "centros de cálculo" enquanto centro de acumulação de informação e associação de poder e conhecimento. $O$ inspetor Rui, que trabalha precisamente na vertente operacional da informação, referiu algumas das possibilidades:

Eu por exemplo na minha função eu recorro ao sistema integrado de informação criminal da PJ, eu recorro ao ficheiro de reclusos, eu recorro, por exemplo, ao ficheiro comum das seguradoras, eu recorro ao Google... [risos] É verdade, eu recorro ao Google. (...) Eu recorro à Europol, à Interpol, tudo são ferramentas.

Os inspetores enaltecem a maior capacidade de recolha e análise de informação, nomeadamente ao nível do que está disponível online (BYRNE; MARX, 2011; DEN BOER, 2011), em particular, pelo recurso às redes sociais. Tal como referiu o inspetor Guilherme:

Hoje, no fundo, com a internet toda a gente põe tudo sobre elas. [...] Antigamente a gente queria saber alguma informação e tinha de andar a perguntar e tinha de ir para o terreno saber [...]. Hoje quase não precisamos 
disso, não é? Hoje quase toda a gente tem a informação no computador [sorriso]. Quase toda a gente tem facebook [...] e está lá tudo.

As pesquisas online e o acesso às redes sociais para obter informação é uma realidade recente que se deve às novas gerações de investigadores. Tal como referiu o inspetor Carlos, "um polícia destas gerações mais novas detém outros recursos e [...] uma capacidade imaginativa de ir à procura de informação em círculos mais diversificados".

Além do policiamento físico é possível agir à distância (CEYHAN, 2005; DEN BOER, 2011) e as bases de dados ilustram esta capacidade. Recorrendo ao exemplo das impressões digitais, se no passado a sua análise era efetuada manualmente e "a olho", o Automated Fingerprint Identification Systems (AFIS) permite agora classificar, armazenar e comparar automaticamente as impressões digitais (COLE, 2001), o que veio, no entender dos inspetores, "facilitar muito a vida em termos de investigação", tornando-a mais célere. A nova vigilância enfatiza, precisamente, a recolha de informação de modo automatizado e que envolve máquinas em vez de humanos.

Os inspetores atribuem maior eficácia à identificação pelo sistema automático e associam o erro ao ser humano, sendo a máquina encarada com maior confiança e fiabilidade (MACHADO, 2012; MACHADO; PRAINSACK, 2012). A observação científica parece ser feita através de máquinas, afigurando-se estes instrumentos como um substituto dos sentidos, estendendo as capacidades naturais do ser humano (VOLTI, 1992; YEARLEY, 1988). A tecnologia representa assim a aplicação da verdade possibilitada pela ciência. Tal como referiu o inspetor Guilherme:

\footnotetext{
Antigamente- [...] o erro era maior, ou melhor, a probabilidade de erro era maior como é lógico, não é? Tudo o que é feito pelo homem é, digamos, imperfeito, e como tal errar também é humano, não é? [...] E errar é muito mais fácil do que se aquilo está preparado cientificamente que é assim, não é?
}

Com o recurso ao sistema automatizado até pode haver uma desresponsabilização dos técnicos pelo facto de haver "um sistema que lhe garante que aquilo que é assim. Enquanto antes tinha que ser ele a garantir que é aquilo" (inspetor Guilherme). Ainda no entender deste inspetor o recurso a estes sistemas poderá não apenas simplificar o trabalho, mas também tornar os inspetores menos 
perspicazes e mais preguiçosos pelo facto de ser possível obter as respostas através da máquina 5 .

Este papel tão perentório da máquina no processo de identificação é contrabalançado pela necessidade de no final os resultados serem averiguados manualmente pelo técnico. Tal como relata o inspetor Alberto, "o sistema dá a probabilidade e depois é comparado manualmente". Contudo, quando os inspetores referem às desvantagens do sistema automatizado que tornam necessária essa verificação manual, a infalibilidade parece recair novamente no ser humano. A este propósito o inspetor Simão explica que "depois o computador só dá os resultados com a matéria prima que Ihe foi lá colocada. Se não foi lá colocada bem a matéria prima, ele não devolve o resultado correto".

Apesar do uso ubíquo de tecnologias de vigilância pela polícia (como é o caso das bases de dados), os inspetores distinguem a realidade policial do CSI (série televisiva Crime Scene Investigation), referindo que ainda estamos longe desse cenário de alta tecnologia e da ciência forense ao serviço da investigação criminal (HUEY, 2010; MACHADO; SANTOS, 2012). A respeito do sistema automatizado de impressões digitais o inspetor Manuel explica como "isto não é tipo CSI. No CSI é que se mete a impressão digital suspeita e a máquina faz correr lá e depois aparece uma fotografia lá e "é este" [refere isto num jeito de troça]". A inexistência de uma base de dados genéticos na prática também ilustra esta realidade tão distante do CSI. Nas palavras do inspetor Manuel: "não há uma base de dados de ADN, a que existe... coitadinha".

\section{A FIGURA TRADICIONAL DE DETETIVE}

Há certos constrangimentos e obstáculos associados aos meios mais inovadores de recolha e gestão de informação e, como tal, é necessário explorar os meios tradicionais e o papel que desempenham na investigação criminal. Os meios "mais antigos" remetem-nos para toda uma panóplia de práticas de vigilância e diligências junto da população com o objetivo de obter informação, implicando para tal um "trabalho de rua". Neste caso, as estratégias procuram o maior número de elementos que permitam identificar o indivíduo ou observar os seus comportamentos

5 Saliente-se que a atitude de perspicácia é descrita pelos inspetores como uma das principais qualidades que o investigador deve possuir. Baltasar, o inspetor entrevistado com mais anos de serviço, diz mesmo que "muitas vezes não é possível recorrermo-nos da ciência para provar o que quer que seja, não é? E aí tem de ser através da atitude, da perspicácia". 
e hábitos, através de um constante "jogo do empurra e do puxa" de informação que se compara a um puzzle "onde se vão juntando peças".

Fazer vigilâncias, seguimentos, rotinar os suspeitos ou recorrer a informadores exemplificam estes meios de obtenção de informação. Segundo o inspetor Filipe, "é desmontar o dia a dia do indivíduo. Claro está, sem que ele se aperceba [sorriso]". O trabalho de "disfarce" e o "passar despercebido" é, de facto, tido como fundamental. Esta informação vai dando "pistas" e é essencial no desenvolvimento da investigação criminal ainda que não possa constar no processo em termos oficiais.

O inspetor Filipe referiu que "em grande parte dos casos o papel [...] quando vem já não faz falta, já nós fomos por outro lado conseguir aquela mesma informação". De facto, é o recurso a meios mais informais de obtenção de informação que permite ultrapassar alguns dos constrangimentos que têm vindo a ser abordados, nomeadamente as dificuldades burocráticas.

Mesmo que não constem oficialmente no processo, essas informações "marginais" que tendem a ficar na margem das folhas de papel e que na sua maioria acabam como "informação de gaveta" são fundamentais. Daí que os inspetores concordem com a sua informatização e, segundo o inspetor Guilherme, a informação é efetivamente sujeita a tratamento por um setor específico da polícia. $O$ que se constata é que o "trabalho tradicional de detetive" continua a ser necessário mesmo que conjugado com a ciência e as novas tecnologias (COLE; LYNCH, 2006; MCCARTNEY, 2006; PURENNE, 2012). A inspetora Paula deixa clara esta necessidade de complementaridade:

\footnotetext{
Uns complementam os outros, porque nós não podemos estar à espera que só os métodos científicos façam as coisas. Nós também temos de andar, de pedalar. Eu acho que ultimamente se tem virado muita gente para os métodos científicos "vamos esperar que estes façam tudo", não podemos. [...] Eu acho que tem de haver um complemento dos nossos passos juntamente com a ciência.
}

\section{CONSIDERAÇÕES FINAIS}

In our societies there are two systems of appeal: nonhuman and superhuman - that is, machines and gods (LATOUR, 1992)

6 Este tipo de trabalho exige algum "engenho" por parte do investigador, principalmente em certos tipos de criminalidade. Exemplo disso é o tráfico de estupefacientes, um trabalho de "muita cusquice" segundo o inspetor Guilherme, que trabalha nesta área. 
O paradigma da tecnofalácia e, concretamente, a falácia da novidade (BYRNE; MARX, 2011) destacam-se nos discursos políticos, assumindo-se que os meios mais inovadores são sempre melhores do que os mais antigos. Este apelo à novidade associa-se ao esforço de "parecer moderno" e, tal como refere Catarina Frois (2008, p. 113), o "grande slogan" em Portugal é, efetivamente, o da modernização. A conceção política da modernização com base no uso de tecnologia surge como símbolo de progresso (FROIS, 2013); contudo, é necessário atender às particularidades do contexto português e refletir sobre os limites associados à crença numa tecnologia capaz de tornar o trabalho policial mais eficaz, tendo por base 0 bicho de sete cabeças que parece dominar a investigação criminal.

Explorando a (in)dependência da tecnologia de vigilância na investigação criminal através da compreensão do sentido atribuído pelos inspetores da PJ às suas práticas, constata-se como a adoção de elementos tecnológicos tem impactos na natureza do trabalho policial. Não obstante a adoção desses elementos, estar sujeita a diversos obstáculos, a inovação tecnológica surge como um dos elementos de um novo profissionalismo no policiamento e a figura tradicional de detetive é sujeita a metamorfoses. Surge a figura de um detetive híbrido como produto de dois tempos diferentes (passado e presente), capaz de associar atores e artefactos e conjugar os meios "duros" e mais antigos com os meios mais "suaves" e inovadores de obtenção de informação.

As considerações no que respeita à dissolução da oposição humano/técnico têm por base a teoria ator-rede e, em particular, um dos seus percursores, Bruno Latour (1992; 2001), que permite refletir sobre o modo como se formam coletivos de elementos humanos e não-humanos e como são distribuídas as competências. Urge assim refletir sobre o papel do ator humano e seus impactos no desenvolvimento e aplicação da tecnologia ou como a mesma pode substituir/moldar a ação humana (LATOUR, 1992), já que "the aura of science and technology as infallible [...] ignores the role of humans [...] in shaping what technologies are developed and how they are designed and applied" (BYRNE; MARX, 2011, p. 33).

Este processo de coconstrução deverá ser vigiado, uma vez que a máquina reúne aliados humanos capazes de renunciar à sua própria agência e "technology is seen to have agency in much the same ways as human elements of the organization" (VAN BRAKEL; HERT, 2011, p. 172). É necessário estar vigilante ao "jogo do olhar" dos que vigiam, uma vez que, tal como referiu Gary Marx, "as novas tecnologias de 
vigilância apresentam dois tipos de problemas opostos. Por um lado, o de não funcionarem e, por outro, funcionarem demasiado bem" (2008, p. 102-103).

\section{AGRADECIMENTOS}

Este artigo integra-se no projeto de doutoramento "A identificação criminal e a identidade do criminoso: perceções de reclusos e agentes de controlo sobre as práticas de vigilância e classificação do corpo delinquente" financiado pela Fundação para a Ciência e Tecnologia (SFRH/BD/70055/2010) do Ministério da Educação e Ciência de Portugal. Agradecemos ainda aos inspetores entrevistados e demais funcionários da instituição pela partilha e disponibilidade.

\section{REFERÊNCIAS}

ABE, Kiyoshi. Technologies of Surveillance. Theor, Cult Soc., v. 23, n. 2-3, p. 265267, 2006.

BYRNE, James; MARX, Gary. Technological Innovations in Crime Prevention and Policing. A Review of the Research on Implementation and Impact. Journal of Police Studies, v. 3, n. 20, p. 17-40, 2011.

CEYHAN, Ayse. Policing by Dossiers: Identification and Surveillance in an Era of Uncertainty and Fear. In: BIGO, Didier; GUILD, Elspeth (Org.). Controlling frontiers: free movement into and within Europe. Londres: Ashgate, 2005. 209-232.

COLE, Simon. Suspect Identities: A History of Fingerprinting and Criminal Identification. Cambridge: Harvard University Press, 2001.

COLE, Simon; LYNCH, Michael. The Social and Legal Construction of Suspects. Annu. Rev. Law Soc. Sci., v. 2, n. 1, p. 39-60, 2006.

COSTA, Susana. Saberes e práticas dos órgãos de polícia criminal na gestão da cena de crime. In: COSTA, Susana; MACHADO, Helena (Org.), A ciência na luta contra o crime: Potencialidades e limites. Vila Nova de Famalicão: Húmus, 2012.

DEN BOER, Monica. Technology-led policing in the European Union: an assessment. Journal of Police Studies, v. 3, n. 20, p. 39-57, 2011.

ERICSON, Richard; HAGGERTY, Kevin. Policing the Risk Society. Oxford: Clarendon Press, 1997.

ERICSON, Richard; SHEARING, Clifford. The Scientification of Police Work. In: Gernot Bhöme e Nico Stehr (Org.), The Knowledge Society. The Growing Impact of Scientific Knowledge on Social Relations. Dordrecht: D. Reidel Publishing Company, 1986. 129-159

FROIS, Catarina. Bases de dados pessoais e vigilância em Portugal: análise de um processo em transição. In: Catarina Frois (Org.), A sociedade vigilante: ensaios sobre identificação, vigilância e privacidade. Lisboa: Imprensa de Ciências Sociais, 2008. 
FROIS, Catarina (Org.). A sociedade vigilante: ensaios sobre identificação, vigilância e privacidade. Lisboa: Imprensa de Ciências Sociais, 2008.

FROIS, Catarina. Peripheral vision: Politics, technology and surveillance. Oxford: Berghahn, 2013.

HUEY, Laura. 'I've seen this on CSl': Criminal investigators' perceptions about the management of public expectations in the field. Crime, Media, Culture, v. 6, n. 1, p. 49-68, 2010.

JOHNSON, Paul; WILLIAMS, Robin; MARTIN, Paul. Genetics and Forensics: Making the National DNA Database. Science studies, v. 16, n. 2, p. 22-37, 2003.

KRUSE, Corinna. Legal storytelling in pre-trial investigations: arguing for a wider perspective on forensic evidence. New Genet Soc, v. 31, n. 3, p. 37-41. 2012.

LATOUR, Bruno. Where are the missing masses? The sociology of a few mundane artifacts. In: BIJKER, Wiebe; LAW, John (Org.), Shaping technology/building society: studies in sociotechnical change. Cambridge: MIT Press, 1992. p. 225-258.

LATOUR, Bruno. Science in Action: How to Follow Scientists and Engineers through Society. Cambridge: Harvard University Press, 2001.

Lyon, David. Surveillance Society: Monitoring Everyday Life. Maidenhead: Open University Press, 2001.

MACHADO, Helena; COSTA, Susana. Biolegalidade, imaginário forense e investigação criminal. Rev. crít. ciênc. soc., v. 97, p. 61-84, 2012.

MACHADO, Helena; PRAINSACK, Barbara. Tracing Technologies. Prisoners' Views in the Era of CSI. Farnham: Ashgate, 2012.

MACHADO, Helena; SANTOS, Filipe. Entre a polícia ficcional e a polícia real: Os usos do DNA na investigação criminal em Portugal. In: DURÃO, Susana; DARCK, Marcio (Org.), Polícia, Segurança e Ordem Pública. Perspetivas portuguesas e brasileiras. Lisboa: Imprensa de Ciências Sociais, 2012. 154-166.

MACHADO, Helena. Crime, Bancos de Dados Genéticos e Tecnologia de DNA na perspetiva de presidiários em Portugal. In: Ciências na vida. Antropologia da Ciência em Perspetiva. São Paulo: Editora Terceiro Nome, 2012. 66-86.

MARX, Gary. Vigilância soft - o crescimento da voluntariedade obrigatória na recolha de dados pessoais: «ó amigo, empresta-me uma amostra de ADN?». In: FROIS, Catarina Frois (Org.), A sociedade vigilante: ensaios sobre identificação, vigilância e privacidade. Lisboa: Imprensa de Ciências Sociais, 2008.

MCCARTNEY, Carole. The DNA Expansion Programme and Criminal Investigation. Brit J Criminol, v. 46, n. 2, p. 175-192, 2006.

PURENNE, Anaik. Police and surveillance in Paris: are the French police becoming knowledge workers and risk managers? In: WALLE, Gudrun Vande; 
HERREWEGEN, Evelien den; ZURAWSKI, Nils (Org.), Crime, Security and

Surveillance. The Hague: Eleven International Publishing, p. 163-176. 2012.

BRAKEL, Rosamunde Van; HERT, Paul De. Policing, surveillance and law in a precrime society: Understanding the consequences of technology based strategies. Technology-Led Policing - Journal of Police Studies, v. 3, n. 20, p. 163-192, 2011.

VOLTI, Rudi. Technology and its creators: who's in charge of whom?. In: SOCIETY and Technological Change. New York: St. Martin's Press, 1992.

YEARLEY, Steven. The status of Scientific Knowledge. In: SCIENCE, Technology and Social Change. Londres: Unwin Hyman, 1988.

WILLIAMS, Robin; JOHNSON, Paul. Genetic Policing: The use of DNA in Criminal Investigations. Cullompton: Willan Publishing, 2008. 